Check for updates

Cite this: RSC Adv., 2019, 9, 6689

Received 12th November 2018

Accepted 19th February 2019

DOI: 10.1039/c8ra09319a

rsc.li/rsc-advances

\title{
Enrichment and separation of steroidal saponins from the fibrous roots of Ophiopogon japonicus using macroporous adsorption resins $\uparrow$
}

\author{
Yi-Feng Zhou, acd Li-Ling Wang, (iD *b Li-Chun Chen, (D) acd Tie-bing Liu, acd \\ Ru-Yi Sha acd and Jian-Wei Mao acd
}

In this study, a simple and effective strategy for the enrichment of total steroidal saponins (TSS) from the fibrous roots of Ophiopogon japonicus (L. f.) Ker-Gawl. (FROJ) using macroporous adsorption resin was systematically developed. XAD-7HP resin was selected from six macroporous resins for further study because of the highest static adsorption and desorption capacities. The static adsorption of TSS on XAD7HP resin fitted well to the Langmuir isotherm model and pseudo second-order kinetic model; the thermodynamics test showed that the adsorption process was spontaneous and exothermic. The dynamic tests on XAD-7HP resin columns demonstrated that the breakthrough volume was 16 bed volume (BV), and $6 \mathrm{BV}$ of $80 \%$ ethanol was suitable for dynamic desorption. In a lab scale-up separation under optimal dynamic conditions, the content of TSS in the resin-enrichment fraction increased from $1.83 \%$ in the crude extracts to $13.86 \%$ by 7.59 -fold with a recovery yield of $82.68 \%$. Three steroidal saponins were obtained from the resin-enrichment fraction, and showed protective effects against oxidized low-density lipoprotein (ox-LDL) induced human umbilical vein endothelial cell (HUVEC) injury. Overall, these results suggested that XAD-7HP resin chromatography was an effective strategy for the large scale enrichment of TSS from FROJ, which showed the potential for functional food and pharmaceutical application.
\end{abstract}

\section{Introduction}

The tuberous roots of Ophiopogon japonicus (L. f.) Ker-Gawl., as a famous traditional medicine (known as Maidong in Chinese), have been used in China to cure acute coughs, sore throats and cardiovascular diseases including thrombotic diseases for many centuries. ${ }^{1-4}$ They have also been used as functional food and local medicine in Japan, Vietnam, etc. ${ }^{5}$ Steroidal saponins, homoisoflavonoids and polysaccharides are the main active ingredients of O. japonicus; steroidal saponins are also known as pharmacodynamic substances for cardiovascular protection and anti-inflammation.,6 Previous studies have indicated that the natural products from the fibrous roots of O. japonicus (FROJ) were similar to those in the tuberous roots of $O$.japonicus, and several steroidal saponins were obtained from FROJ. ${ }^{7-14}$ Therefore, FROJ could be

${ }^{a}$ School of Biological and Chemical Engineering, Zhejiang University of Science and Technology, No. 318 Liuhe Road, Hangzhou, 310023, China

${ }^{b}$ Zhejiang Academy of Forestry, No. 399 Liuhe Road, Hangzhou, 310023, China. E-mail:echo22239@163.com

'Zhejiang Provincial Key Lab for Chemical and Biological Processing Technology of Farm Produces, No. 318 Liuhe Road, Hangzhou, 310023, China

${ }^{d}$ Zhejiang Province Collaborative Innovation Center of Agricultural Biological Resources Biochemical Manufacuring, No. 318 Liuhe Road, Hangzhou, 310023, China $\uparrow$ Electronic supplementary information (ESI) available. See DOI: $10.1039 / \mathrm{c} 8 \mathrm{ra09319a}$ an important source for research and development in functional food and pharmaceutical applications, which can also reduce the consumption of the medicinal parts of tuberous roots and take full advantage of the plant resources.

With excellent selectivity, high recovery and efficiency, macroporous adsorption resins are successfully applied for enrichment and separation of natural products, such as flavonoids, ${ }^{15,16}$ alkaloids, ${ }^{17}$ saponins,${ }^{18}$ polyphenols, ${ }^{19,20}$ organic acid, ${ }^{21,22}$ polysaccharides, ${ }^{23,24}$ etc., from the natural complex extracts. To our knowledge, though macroporous resins have previously used in the purification process of the steroidal saponins from $O$. japonicus, there is little research on the adsorption and desorption behaviors of steroidal saponins on macroporous resins. In this study, the static and dynamic adsorption/desorption characteristics of total steroidal saponins (TTS) from FROJ have been systematically investigated. In addition, three steroidal saponins were obtained from the resinenrichment fraction, and their bioactivities of endothelium protection were evaluated in vitro.

\section{Experimental}

\subsection{Chemicals and apparatus}

Macroporous resins of DM301, X-5 and S-8 were purchased from Anhui Sanxing Resin technology Company, China. 
Macroporous resins of XAD16, XAD1180 and XAD-7HP was obtained from H\&E Company, Beijing, China. All these resin were pretreated before use. The resins were successively soaked in ethanol $(95 \%, \mathrm{v} / \mathrm{v}), 5 \% \mathrm{HCl}$ and $5 \% \mathrm{NaOH}$ for $12 \mathrm{~h}$, and washed thoroughly with pure water after every soak step. Finally, the resins were dried by an oven at $60{ }^{\circ} \mathrm{C}$ to constant weight.

The reference substance of ruscogenin was purchased from the National Institutes for Food and Drug Control (Beijing, China). HPLC grade acetonitrile was obtained from TEDIA Company (Fairfield, OH, USA). The pure water was prepared by a Millipore Direct-Q3 water system (Bedford, MA, USA). Silica gel (200-300 mesh, Marine Chemical Factory, Qingdao, China) and ODS silica gel (50 mesh, YMC, Tokyo, Japan) were applied for column chromatography (CC) for the resin enrichment fraction. Fractions obtained from CC were analyzed by TLC using silica gel GF 254 plates (Marine Chemical Factory, Qingdao, China). All other solvents used in this study were of analytical grade from Lingfeng Chemical Reagent Company (Shanghai, China).

A TGCXZ-2B ultrasonic-assisted extraction equipment (Hongxianglong technology company, Beijing, China) was used for extraction of FROJ. The UV spectra were analyzed by a UV2600 spectrophotometer (Shimadzu Corporation, Tokyo, Japan). A LC-8A preparative high-performance liquid chromatography (PHPLC) and a LC-20AD HPLC were used for HPLC purification and analysis, respectively (Shimadzu Corporation, Tokyo, Japan). The HPLC-MS analysis was applied on a Xevo G2XS QTOF Mass Spectrometer (Waters Corporation, Milford, USA) in negative mode. The nuclear magnetic resonance (NMR) spectrometer determined by a Bruker Avance 500 NMR (Bruker Corporation, Faellanden, Switzerland).

\subsection{Preparation of sample solution}

The FROJ was obtained from farms of Cixi city (Zhejiang province, China) in May 2016. The samples were ground into powders and stored in the desiccator until use. The powdered FROJ were extracted with 10 -fold volumes of $80 \%$ ethanol in batches. The crude extracts were immediately filtrated, concentrated and dried. The pure water was added to obtain TSS solutions at different concentrations.

\subsection{Determination of TSS content}

2.3.1 The establishment of the standard curve. The content of TSS in the present study was determined according to China Pharmacopoeia (2015 version) method with some modification. ${ }^{25}$ Ruscogenin was used as reference standard for external standard curve. A series of standard solutions in methanol (4$40 \mu \mathrm{g} \mathrm{mL}^{-1}$ ) were added into test tubes and evaporated in water bath. Then $5 \mathrm{~mL}$ perchloric acid were added and incubation at $80{ }^{\circ} \mathrm{C}$ for $15 \mathrm{~min}$. After cooling by the ice water, the absorbances of the standard solutions were determined at $397 \mathrm{~nm}$. The calibration curve of TSS content was $Y=0.0264 X-0.0490\left(R^{2}=\right.$ $0.9992)$, where $X$ was their concentration $\left(\mu \mathrm{g} \mathrm{mL}{ }^{-1}\right)$ and $Y$ was the value of absorbance.

2.3.2 Determination of samples. The suitable TSS content of extracts (equal to 0.5-2 g FROJ) was dissolved in $10 \mathrm{~mL}$ water and extracted by $10 \mathrm{~mL}$ water-saturated $n$-butanol for five consecutive times. Then the extract fraction was washed by $5 \mathrm{~mL}$ ammonia solution for two consecutive times and dried under vacuum. The residue was dissolved in $25 \mathrm{~mL} 80 \%$ menthol, and $1 \mathrm{~mL}$ sample solution was added into test tubes and evaporated in water bath. Then the subsequent processes were operated similarly according to the standard solution in the Section 2.3.1. Finally, the concentration of TSS was calculated using the calibration curve.

\subsection{Static adsorption and desorption tests}

2.4.1 Static adsorption and desorption properties of the different resins. First, $25 \mathrm{~mL}$ of FROJ sample solution with initial TSS concentration of $0.830 \mathrm{mg} \mathrm{mL}^{-1}$ (equal to $0.1 \mathrm{~g}$ FROJ extract in every $\mathrm{mL}$ solution) was added into $100 \mathrm{~mL}$ flasks with the pretreated different resins ( $0.1 \mathrm{~g}$ dry weight). Next, the flasks with stoppers were shaken in a constant temperature shaker at $25{ }^{\circ} \mathrm{C}$ with $120 \mathrm{rpm}$ for $24 \mathrm{~h}$, and the sample solution after adsorption equilibrium was filtrated to analyze the TSS concentration. Then, the resins was washed by pure water, and $25 \mathrm{~mL}$ of $80 \%$ aqueous ethanol was added into the flasks for desorption. Finally, the flasks with stoppers were shaken in a constant temperature shaker at $25{ }^{\circ} \mathrm{C}$ with $120 \mathrm{rpm}$ for $6 \mathrm{~h}$, and the desorption solution was determined.

The static absorption capacity was calculated with the formula:

$$
Q_{\mathrm{e}}=\frac{\left(C_{0}-C_{\mathrm{e}}\right) V_{\mathrm{i}}}{W}
$$

where $Q_{\mathrm{e}}\left(\mathrm{mg} \mathrm{g}^{-1}\right)$ is the adsorption capacity of TSS at adsorption equilibrium; $C_{0}\left(\mathrm{mg} \mathrm{mL}^{-1}\right)$ and $C_{\mathrm{e}}\left(\mathrm{mg} \mathrm{mL}^{-1}\right)$ are the initial and equilibrium concentration of TSS in the sample solutions, respectively; $V_{\mathrm{i}}(\mathrm{mL})$ is the volume of the initial sample solution; $W(\mathrm{~g})$ is the dry weight of the tested resin.

The static absorption capacity was calculated with the formula as follows:

$$
\begin{gathered}
Q_{\mathrm{d}}=\frac{C_{\mathrm{d}} V_{\mathrm{d}}}{W} \\
D=\frac{C_{\mathrm{d}} V_{\mathrm{d}}}{\left(C_{0}-C_{\mathrm{e}}\right) V_{\mathrm{i}}} \times 100 \%
\end{gathered}
$$

$Q_{\mathrm{d}}\left(\mathrm{mg} \mathrm{g}^{-1}\right)$ is the desorption capacity of TSS at desorption equilibrium, and $D(\%)$ is the desorption ratio; $C_{\mathrm{d}}\left(\mathrm{mg} \mathrm{mL}^{-1}\right)$ is the TSS concentration in the desorption solution, $V_{\mathrm{d}}(\mathrm{mL})$ is the volume of the desorption solution.

2.4.2 Adsorption isotherms and thermodynamics of the selected resin. The dried FROJ extract was diluted to different initial TSS concentrations $(0.415,0.830,1.038,1.245,1.660$, $2.075 \mathrm{mg} \mathrm{mL}{ }^{-1}$ ) with pure water. And these sample solutions $(25 \mathrm{~mL})$ were added into $100 \mathrm{~mL}$ flasks with the equal pretreated resins ( $0.1 \mathrm{~g}$ dry weight). Then the flasks with stoppers were shaken at $120 \mathrm{rpm}$ for $24 \mathrm{~h}$ in a constant temperature shaker at three different temperatures with 25,35 and $45{ }^{\circ} \mathrm{C}$, respectively. The initial and equilibrium concentration of TSS in the sample solutions at different temperatures were determined. Moreover, the two well-known theoretical isotherm models were applied to 
analyze the adsorption correlations between the solute and the resins.

The Langmuir model and its rearranged linear form can be expressed as

$$
\begin{gathered}
Q_{\mathrm{e}}=\frac{Q_{\mathrm{m}} C_{\mathrm{e}}}{K_{\mathrm{L}}+C_{\mathrm{e}}} \\
\frac{C_{\mathrm{e}}}{Q_{\mathrm{e}}}=\frac{1}{K_{\mathrm{L}} Q_{\mathrm{m}}}+\frac{C_{\mathrm{e}}}{Q_{\mathrm{m}}}
\end{gathered}
$$

where $Q_{\mathrm{e}}\left(\mathrm{mg} \mathrm{g}^{-1}\right)$ and $C_{\mathrm{e}}\left(\mathrm{mL} \mathrm{mg}^{-1}\right)$ are same as mentioned above; $K_{\mathrm{L}}$ is the Langmuir constant, and $Q_{\mathrm{m}}\left(\mathrm{mg} \mathrm{g}^{-1}\right)$ is the calculated maximum adsorption capacity, theoretically.

The Freundlich model and its rearranged linear form can be expressed as

$$
\begin{gathered}
Q_{\mathrm{e}}=K_{\mathrm{F}} C_{\mathrm{e}}{ }^{1 / n} \\
\ln Q_{\mathrm{e}}=\ln K_{\mathrm{F}}+1 / n \ln C_{\mathrm{e}}
\end{gathered}
$$

where $Q_{\mathrm{e}}\left(\mathrm{mg} \mathrm{g}^{-1}\right)$ and $C_{\mathrm{e}}\left(\mathrm{mL} \mathrm{mg}^{-1}\right)$ are same as mentioned above; $K_{\mathrm{F}}$ is the Freundlich constant, and $1 / n$ reflect an empirical constant for the adsorption driving force.

In addition, the adsorption thermodynamics were calculated with the equations as follows:

$$
\begin{aligned}
& \Delta G=-R T \ln K_{\mathrm{c}} \\
& \ln K_{\mathrm{c}}=\frac{\Delta S}{R}-\frac{\Delta H}{R T}
\end{aligned}
$$

where $\Delta G\left(\mathrm{~kJ} \mathrm{~mol}^{-1}\right)$ is Gibbs free energy change; $\Delta H\left(\mathrm{~kJ} \mathrm{~mol}^{-1}\right)$ is enthalpy change, $\Delta S\left(\mathrm{~J} \mathrm{~mol}^{-1} \mathrm{~K}^{-1}\right)$ is entropy change; $R$ is the ideal gas constant $\left(8.314 \mathrm{~J} \mathrm{~mol}^{-1} \mathrm{~K}^{-1}\right), T(\mathrm{~K})$ is the absolute temperature; and $K_{\mathrm{c}}$ is thermodynamic equilibrium constant, which is determined by plotting $\ln \left(Q_{\mathrm{e}} / C_{\mathrm{e}}\right)$ versus $Q_{\mathrm{e}}$ and extrapolating to zero $Q_{\mathrm{e}^{26}}$

2.4.3 Static adsorption and desorption kinetics of the selected resin. The experiment of static adsorption and desorption was conducted according to the method described above in the Section 2.4.1. The FROJ sample solution (TSS initial concentration of $1.245 \mathrm{mg} \mathrm{mL}^{-1}$ ) was added into a flask with a stopper to mix with the pretreated resin. In adsorption process, the TSS content in the supernatant was analyzed at $10 \mathrm{~min}, 1 \mathrm{~h}, 2 \mathrm{~h}, 4 \mathrm{~h}, 6 \mathrm{~h}, 8 \mathrm{~h}, 10 \mathrm{~h}, 12 \mathrm{~h}, 15 \mathrm{~h}$, and $18 \mathrm{~h}$, respectively. After static adsorption equilibrium, $80 \%$ aqueous ethanol were added to investigate desorption process. The TSS concentration in the solution was determined at $15 \mathrm{~min}$, $30 \mathrm{~min}, 45 \mathrm{~min}, 1 \mathrm{~h}, 1.5 \mathrm{~h}, 3 \mathrm{~h}$ and $6 \mathrm{~h}$, respectively.

To understand the mechanism involved in the adsorption process, the adsorption kinetics data were further fitted by the pseudo-first and pseudo-second-order models.

The pseudo first order model

$$
\ln \left(Q_{\mathrm{e}}-Q_{t}\right)=\ln Q_{\mathrm{e}}-K_{1} t
$$

The pseudo second order model

$$
\frac{t}{Q_{t}}=\frac{1}{K_{2} Q_{\mathrm{e}}^{2}}+\frac{t}{Q_{\mathrm{e}}}
$$

where $k_{1}$ and $k_{2}$ are the rate constants of the pseudo-first-ordermodel, the pseudo-second-order-model, respectively; $Q_{t}(\mathrm{mg}$ $\left.\mathrm{g}^{-1}\right)$ and $Q_{\mathrm{e}}\left(\mathrm{mg} \mathrm{g}^{-1}\right)$ are the TSS adsorption capacity at time $t(\mathrm{~h})$ and adsorption equilibrium, respectively.

\subsection{Dynamic adsorption and desorption tests}

During the dynamic adsorption and desorption process, $1 \mathrm{~g}$ pretreated XAD-7HP resins $(1 \mathrm{BV}=5 \mathrm{~mL})$ were loaded onto a series of $\mathrm{PE}$ columns $(1.6 \mathrm{~cm} \times 5 \mathrm{~cm})$, and the flow rate was kept at 2 $\mathrm{BV} \mathrm{h}^{-1}$.

2.5.1 Optimization of loading amounts for adsorption (dynamic breakthrough curves). $200 \mathrm{~mL}$ FROJ sample solution (TSS initial concentration of $1.245 \mathrm{mg} \mathrm{mL}^{-1}$ ) was loaded onto the PE column by a constant flow pump. The effluent were collected and analyzed to optimize the suitable loading amounts.

2.5.2 Selection of ethanol concentrations for dynamic desorption. After the dynamic adsorption equilibrium, the resin column was rinsed with $4 \mathrm{BV}$ pure water firstly, and then $4 \mathrm{BV}$ with different ethanol concentrations $(20 \%, 40 \%, 60 \%, 80 \%$, $90 \%)$. The desorbed solutions at each ethanol concentration were collected and measured.

2.5.3 Optimization of the eluent volumes with the selected ethanol concentration (dynamic desorption curves). With the optimum loading amount and ethanol concentration, the desorption volumes of ethanol solution was evaluated, and the desorbed solutions at every BV were collected and analyzed.

\subsection{Lab scale-up enrichment and further isolation of steroidal saponins}

To validate the optimum dynamic conditions, a lab scale-up separation was conducted on a glass column $(6 \mathrm{~cm} \times 100 \mathrm{~cm})$ at a constant flow rate of $2 \mathrm{BV} \mathrm{h}^{-1} .32 \mathrm{~L}$ sample solution with TSS concentration $1.245 \mathrm{mg} \mathrm{mL}^{-1}$ (equal to $600 \mathrm{~g}$ FROJ extract) was subjected to a XAD7HP resin column $(1 \mathrm{BV}=2 \mathrm{~L})$. After the sample adsorption finished, the column was successively eluted by $4 \mathrm{BV}$ of pure water, $4 \mathrm{BV}$ of $20 \%$ ethanol and $6 \mathrm{BV}$ of $80 \%$ ethanol. The resin-enrichment fraction of $80 \%$ ethanol effluents was collected, concentrated and dried to analyze TSS contents and recoveries.

The resin-enrichment fraction was further isolated as the method described by $\mathrm{Wu}$ et al. with some modifications. ${ }^{4}$ The fraction (28 g) was subjected to silica gel column chromatography eluted with $\mathrm{CHCl}_{3}-\mathrm{MeOH}-\mathrm{H}_{2} \mathrm{O}(90: 10: 1$ to $10: 90: 5, \mathrm{v} /$ v) to afford eleven sub-fractions (SF. a-k). SF. e was subjected to ODS column eluted with a gradient $\mathrm{MeOH}-\mathrm{H}_{2} \mathrm{O}(20: 80$ to $100: 0, \mathrm{v} / \mathrm{v}$ ) to afford four fractions (SF. e1-4). Fr. e3 was further purified using a PHPLC with $\mathrm{CH}_{3} \mathrm{CN}-\mathrm{H}_{2} \mathrm{O}(40: 60, \mathrm{v} / \mathrm{v})$ to afford S1 (41.6 mg). Similarly, SF. $\mathrm{f}$ and SF. $g$ were firstly separated on an ODS column with a gradient $\mathrm{MeOH}-\mathrm{H}_{2} \mathrm{O}(20: 80$ to $100: 0$, $\mathrm{v} / \mathrm{v}$ ) to afford four fractions (SF. f1-4, SF. g1-4), respectively; then, $\mathrm{S} 2(23.8 \mathrm{mg}$ ) and S3 (41 mg) were accordingly obtained from SF. f2 and SF. g2 by PHPLC with $\mathrm{CH}_{3} \mathrm{CN}-\mathrm{H}_{2} \mathrm{O}$ (40: 60, v/v). 
2.7 The effect of three steroidal saponins on oxidized lowdensity lipoprotein (ox-LDL)-induced human umbilical vein endothelial cells (HUVECs) injury

The HUVECs and their specific medium catalog No. CM-0122 were obtained from Procell Life Science \& Technology Co., Ltd. (Wuhan, China). Cell culture and viability measurement were carried out according to previous studies with some modifications. ${ }^{27}$ After cultured in a humidified incubator with $5 \% \mathrm{CO}_{2}\left(37^{\circ} \mathrm{C}\right)$ for several days, HUVECs were enzymatically harvested and counted in a haemocytometer and subcultured in 96-well plates at a density of about $5 \times 10^{3}$ cell per well. Subsequently, a series of concentrations of three steroidal saponins (S1, S2 and S3 with 0, 10, 20, 40 and $50 \mu \mathrm{mol} \mathrm{L}^{-1}$ ) were added and cultivated for $24 \mathrm{~h}$ in the medium. Then, the HUVECs incubated with ox-LDL $\left(50 \mu \mathrm{g} \mathrm{mL} \mathrm{mL}^{-1}\right)$ for $60 \mathrm{~min}$. Finally, the medium was discarded and $100 \mu \mathrm{L}$ fresh medium containing $10 \%$ Cell Counting Kit-8 (CCK-8) was added to each well for further $1 \mathrm{~h}$ at $37{ }^{\circ} \mathrm{C}$. The absorbance was determined at a wavelength of $450 \mathrm{~nm}$ with a Thermo Varioskan Flash (Waltham, MA, USA).

\subsection{Statistical analysis}

The analyses were conducted in triplicate in the Section 2.4 and 2.5, and were performed for five independent experiments in the Section 2.7. The experimental results were represented as the mean \pm standard deviation. The significance of the difference between the experimental runs was identified based on one-way analysis of variance.

\section{Results and discussion}

\subsection{The preliminary selection of the resins}

The static adsorption and desorption capacities are the important indexes for selection of the macroporous adsorption resin, and they are related with their physical and chemical properties of polarities, surface area and average pore diameter, etc. Considering steroidal saponins comprised of both non-polar sapogenin skeleton and polar sugar chains, six resins with different characteristics (Table 1) were selected in this study.

As shown in Fig. 1, the weak-polar XAD-7HP and non-polar XAD-1180 displayed higher adsorption capacities than other four resins, which implied that the polarities of resins is not the only factor affecting the TSS adsorption on resins. The higher adsorption capacity of TSS on the two resins may be explained

Table 1 Physical and chemical properties of the macroporous resins

\begin{tabular}{llll}
\hline Resins & Polarity & $\begin{array}{l}\text { Surface area } \\
\left(\mathrm{m}^{2} \mathrm{~g}^{-1}\right)\end{array}$ & $\begin{array}{l}\text { Average pore } \\
\text { diameter }(\mathrm{nm})\end{array}$ \\
\hline XAD16 & Non-polar & 800 & 15 \\
X-5 & Non-polar & $500-600$ & $29-30$ \\
XAD1180 & Non-polar & 450 & 40 \\
XAD-7HP & Weak-polar & 500 & 45 \\
DM301 & Moderately-polar & $330-380$ & $13-17$ \\
S-8 & Polar & $100-120$ & $28-30$
\end{tabular}

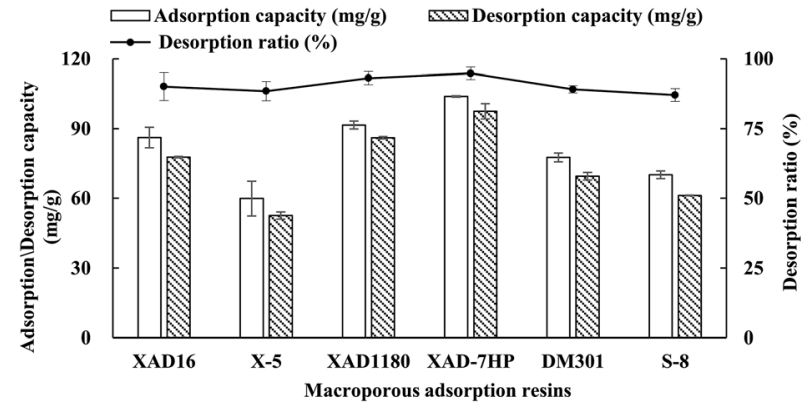

Fig. 1 Adsorption, desorption capacities and desorption ratio of total steroidal saponins (TSS) from the fibrous roots of Ophiopogon japonicus (FROJ) on different resins $(n=3)$.

by their relatively greater pore diameter and surface area as described in previous studies. ${ }^{28-30}$

Meanwhile, XAD-7HP also had the highest desorption capacitates and desorption ratio, although all the desorption radios of six resins were nearly $90 \%$ (Fig. 1). Therefore, XAD7HP was chosen to study the adsorption and desorption behaviors of steroidal saponins.

\subsection{Adsorption isotherms of TSS on XAD-7HP resin}

The adsorption isotherms of TSS on XAD-7HP resin at three temperatures are shown in Fig. 2A. The adsorption capacity of TSS on XAD-7HP resin increased rapidly with the increment of initial concentration, and increased slowly after the initial TSS concentration higher than $1.245 \mathrm{mg} \mathrm{mL}^{-1}$; moreover, the rise of temperature decreased the adsorption capacity on the resin at accordingly initial concentration, indicating an exothermic adsorption process. In views of these experimental results, the initial TSS concentration at $1.245 \mathrm{mg} \mathrm{mL}^{-1}$ and temperature at $25{ }^{\circ} \mathrm{C}$ were selected for further tests, respectively.

As listed in Table 2, $Q_{\mathrm{m}}$ in Langmuir equation is decreased with the increasing temperature, which was consistent with the experimental results; the $1 / n<1$ in Freundlich equation suggested that the steroidal saponins in sample solution can be easily adsorbed on the XAD-7HP resin. As illustrated in the linear plots of Langmuir model (Fig. 2B) and Freundlich model (Fig. 2C), the Langmuir model had a better correlation with high correlation coefficient $\left(R^{2}>0.99\right)$ (Table 2) within the concentration and temperature ranges in this study. Therefore, there may be a monolayer adsorption behavior involved in the steroidal saponins of FROJ solution adsorption onto the XAD7HP resins.

\subsection{Adsorption thermodynamics on XAD7HP resin}

As presented in Table 3, the parameters of the adsorption thermodynamics revealed the inherent energy change in the adsorption process. The negative values of $\Delta G$ showed the adsorption of the steroidal saponins is spontaneous at three different temperatures. The value of $\Delta H$ was negative, indicating the adsorption process is exothermic and relative lower temperature is beneficial for the TSS adsorption on XAD-7HP resin. The result is consistent with the findings in adsorption 

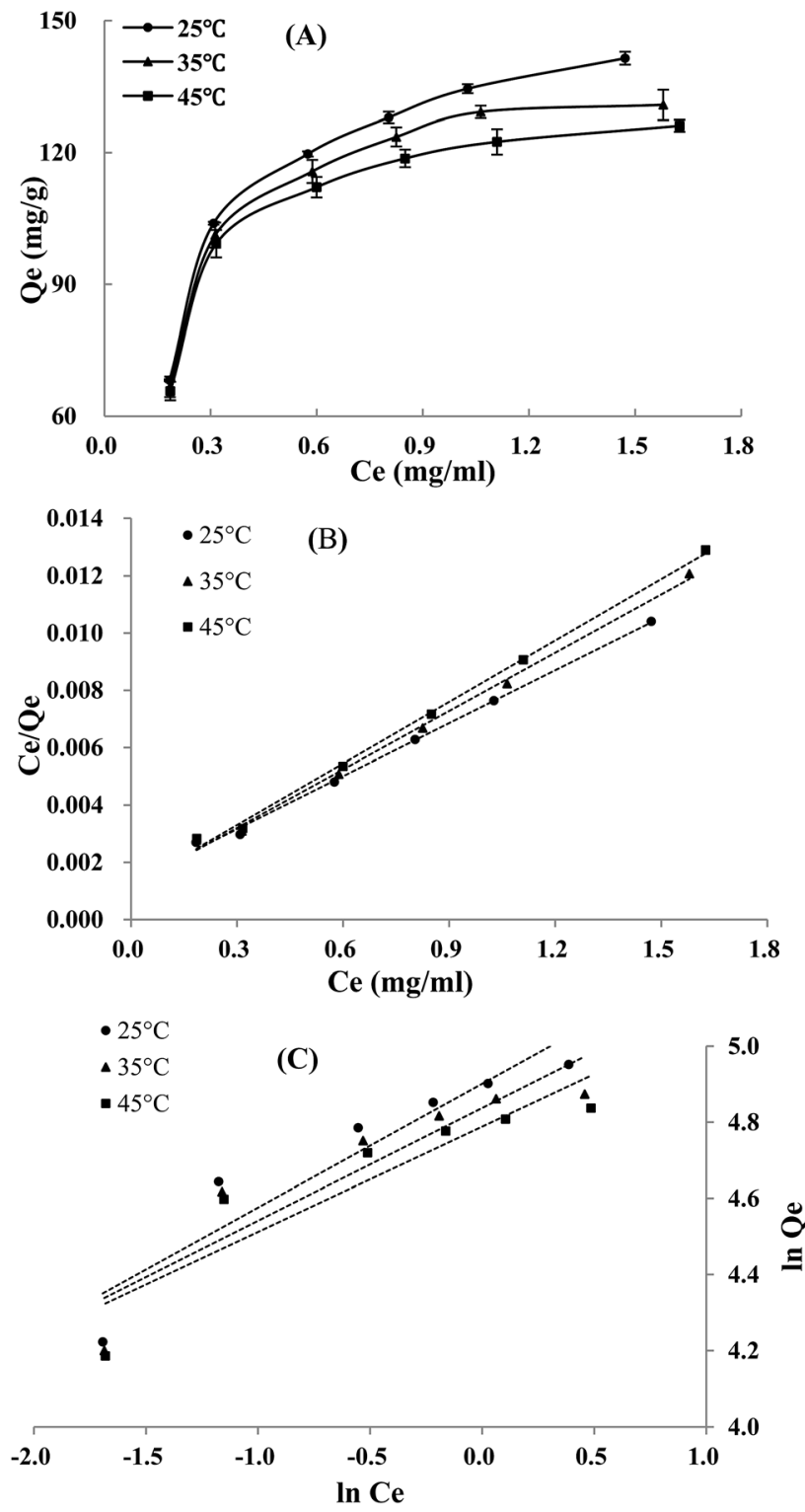

Fig. 2 Adsorption isotherms of TSS on XAD-7HP resin at different temperatures $(n=3)(\mathrm{A})$; linear correlation plots of TSS on XAD-7HP resin at different temperatures based on Langmuir model (B) and Freundlich model (C).

isotherms. Besides, the positive value of $\Delta S$ implied the increasing randomness at the resin-solute interface when the solutes were adsorbed onto the absorbent. ${ }^{31,32}$

Table 2 Langmuir and Freundlich constants at different temperatures $(n=3)$

\begin{tabular}{|c|c|c|c|c|c|c|}
\hline \multirow{2}{*}{$\begin{array}{l}\text { Temperature } \\
\left({ }^{\circ} \mathrm{C}\right)\end{array}$} & \multicolumn{3}{|c|}{ Langmuir equation } & \multicolumn{3}{|c|}{ Freundlich equation } \\
\hline & $K_{\mathrm{L}}$ & $Q_{\mathrm{m}}$ & $R^{2}$ & $K_{\mathrm{F}}$ & $1 / n$ & $R^{2}$ \\
\hline 25 & 0.210 & 161.29 & 0.997 & 134.44 & 0.325 & 0.884 \\
\hline 35 & 0.176 & 147.06 & 0.996 & 126.13 & 0.296 & 0.846 \\
\hline 45 & 0.167 & 138.89 & 0.997 & 120.10 & 0.276 & 0.836 \\
\hline
\end{tabular}

Table 3 Static adsorption thermodynamic parameters of TSS on XAD7HP resin $(n=3)$

\begin{tabular}{llll}
\hline$T\left({ }^{\circ} \mathrm{C}\right)$ & $\begin{array}{l}\Delta G \\
\left(\mathrm{~kJ} \mathrm{~mol}^{-1}\right)\end{array}$ & $\begin{array}{l}\Delta H \\
\left(\mathrm{~kJ} \mathrm{~mol}^{-1}\right)\end{array}$ & $\begin{array}{l}\Delta S \\
\left(\mathrm{~J} \mathrm{~mol}^{-1} \mathrm{~K}^{-1}\right)\end{array}$ \\
\hline 25 & -4.948 & -1.338 & 21.085 \\
35 & -5.151 & & \\
45 & -5.370 & &
\end{tabular}

\subsection{Static adsorption and desorption kinetics on XAD-7HP resin}

It could be seen in Fig. 3A, the adsorption capacity of TSS on XAD-7HP resin increased significantly within the first $6 \mathrm{~h}$, then rised slowly thereafter, and reached equilibrium at approximately $12 \mathrm{~h}$. The long equilibrium time may be attributing to
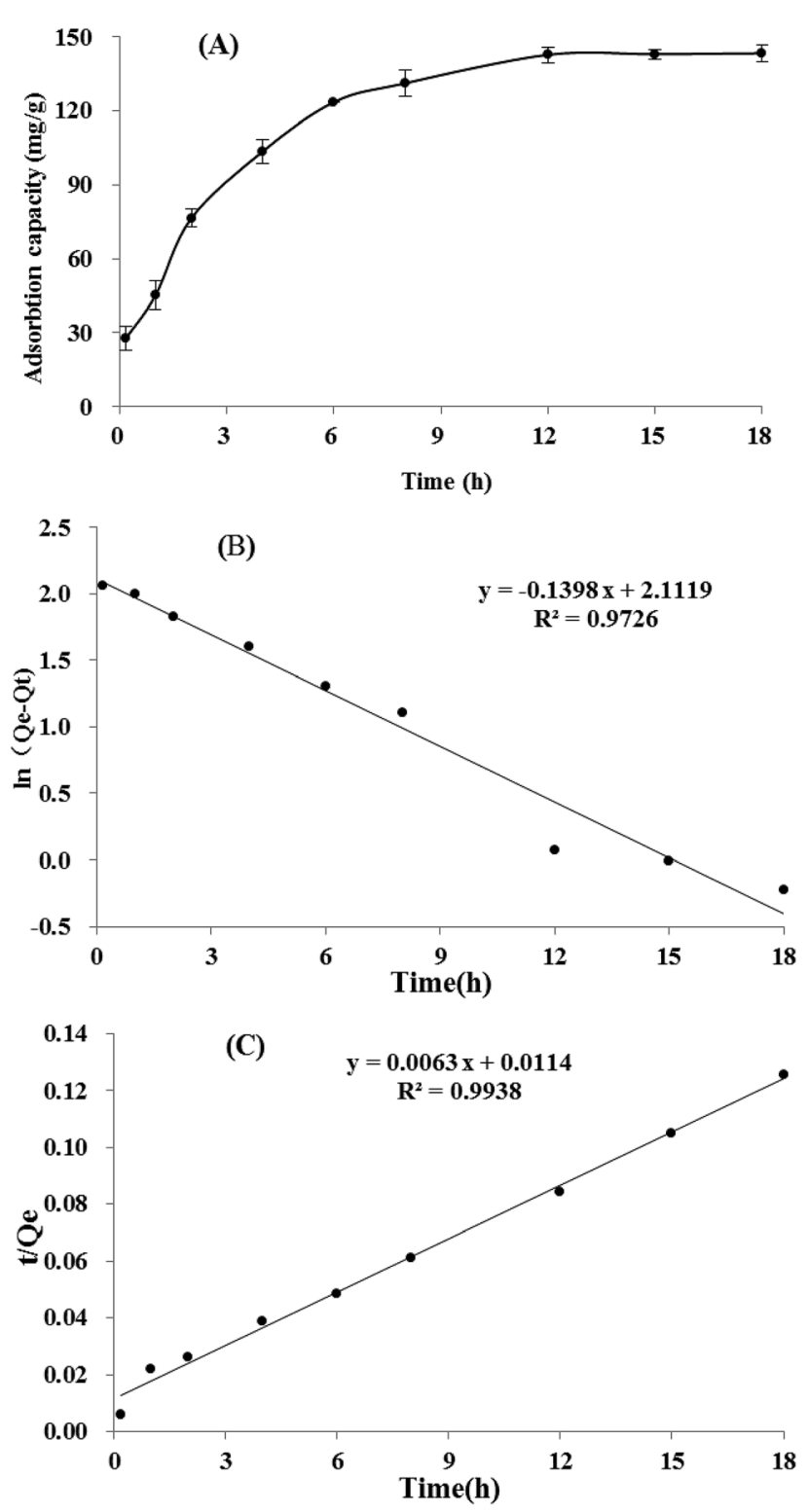

Fig. 3 Static adsorption kinetics of TSS on XAD-7HP resin at $25^{\circ} \mathrm{C}(n=$ 3) (A); linear correlation plots of TSS on XAD-7HP resin at $25^{\circ} \mathrm{C}$ based on first order kinetic model (B) and second order kinetic model (C). 
Table 4 Static adsorption kinetic model rate constants $(n=3)$

\begin{tabular}{llll}
\hline Model & $K$ & $Q_{\mathrm{e}}$ & $R^{2}$ \\
\hline $\begin{array}{l}\text { Pseudo first order } \\
\begin{array}{l}\text { Pseudo second } \\
\text { order }\end{array}\end{array}$ & 0.3219 & 129.39 & 0.9726 \\
& 0.0063 & 158.73 & 0.9938 \\
\end{tabular}

too many impurities and low concentration of TSS in crude extract. Based on the adsorption data above, two linear correlation plots of the pseudo first-order model and the pseudo second-order model are illustrated in Fig. 3B and $\mathrm{C}$, and the model rate constants are shown in Table 4 . The adsorption kinetics is fitted well to the pseudo second-order model with the better correlation index $\left(R^{2}=0.9938\right)$, which indicated the adsorption process may be controlled by two or more ratelimiting steps. Similar observation was made in previous studies using XAD7HP resins on anthocyanin from jamun. ${ }^{33}$ Meanwhile, the desorption process of TSS on XAD-7HP was completed within $2 \mathrm{~h}$ (Fig. 4), which suggested a good and fast desorption effect of TSS from the resins.

\subsection{Dynamic adsorption/desorption of TSS on XAD-7HP resin column}

3.5.1 Dynamic breakthrough curves on resin. The break point is important reference values for scale-up of the loading amount of sample solutions. In our study, the breakage point is defined by the ratio of the effluent concentration reaching to the $10 \%$ of the initial concentration in sample solution. ${ }^{21,32}$ As shown in Fig. 5A, TSS concentration in effluent increased slowly before $20 \mathrm{BV}$, then increased rapidly from 20-30 BV, and showed a slope tendency after $30 \mathrm{BV}$. Finally, the $16 \mathrm{BV}$ of loading amount was chosen for the dynamic adsorption according to the experimental results.

3.5.2 Effect of ethanol concentration. The suitable ethanol concentration is an important factor for the dynamic desorption process. As shown in Fig. 5B, the TSS concentration increased significantly with $40 \%$ ethanol elution, then reached the maximum at $80 \%$ ethanol elution, and decreased at $90 \%$

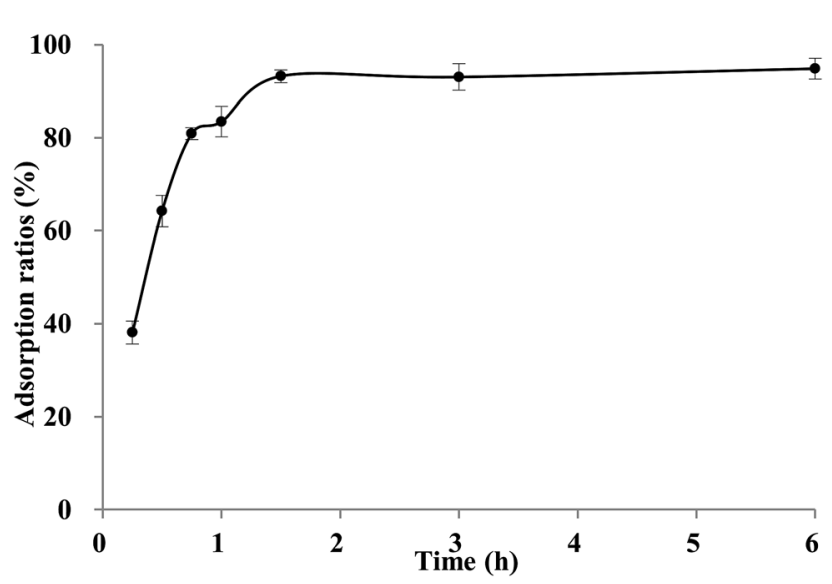

Fig. 4 Static desorption kinetics of TSS on XAD-7HP resin at $25^{\circ} \mathrm{C}(n=$ 3).
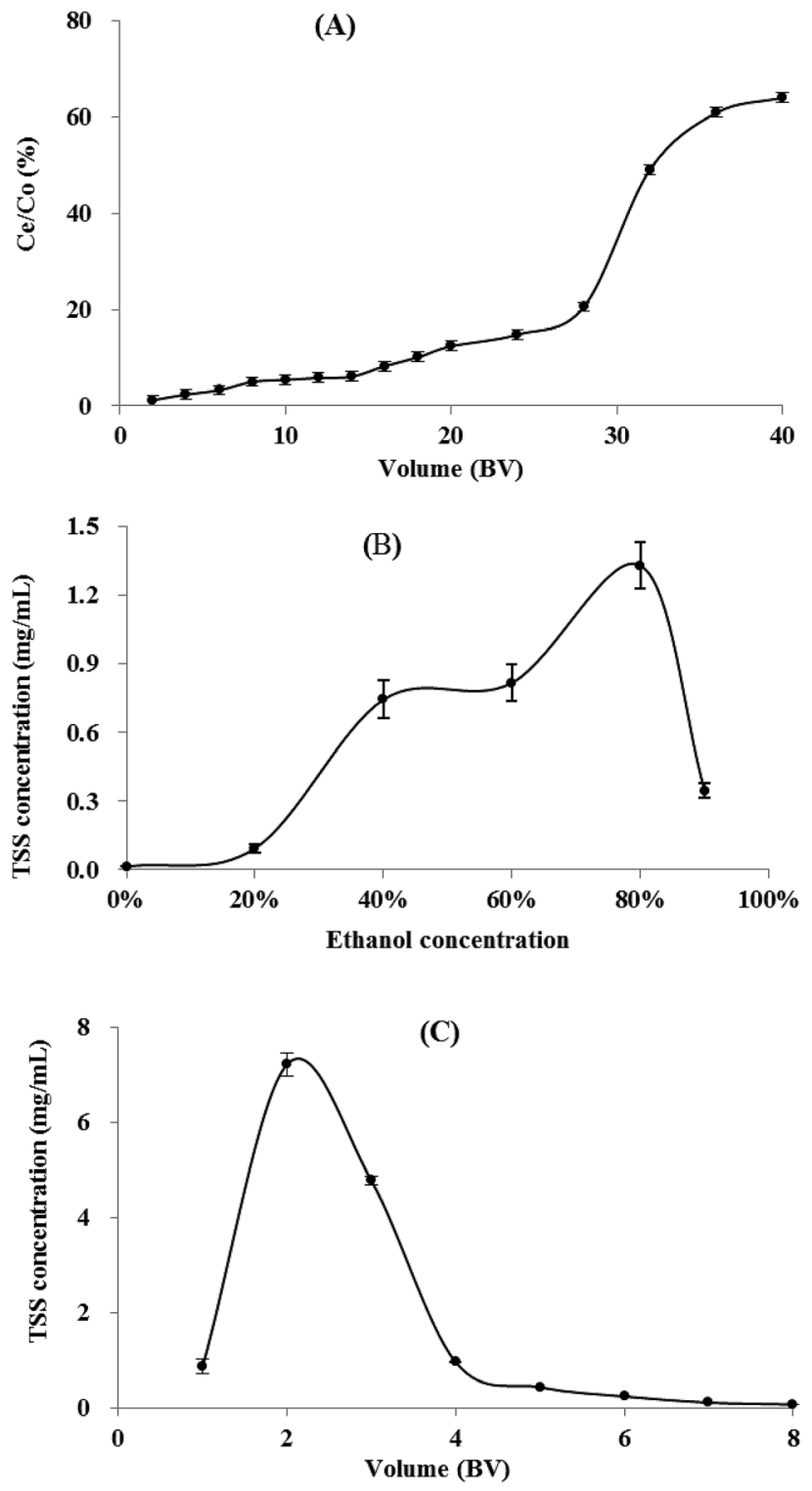

Fig. 5 Factors affect the adsorption and desorption properties of XAD-7HP resin $(n=3)$ (A) dynamic breakthrough curves of TSS on column; (B) effect of ethanol concentration on TSS desorption; (C) dynamic desorption curves of TSS on column.

ethanol elution. Therefore, taking the cost and efficiency into account, $80 \%$ ethanol (v/v) was the best selection.

3.5.3 Dynamic desorption curves with the selected ethanol concentration. Fig. $5 \mathrm{C}$ indicated the dynamic desorption curves of TSS on XAD-7HP resin with $80 \%$ ethanol. The TSS

Table 5 The contents and recoveries of TSS on lab scale-up separation

\begin{tabular}{lccl}
\hline & Weight $(\mathrm{g})$ & $\begin{array}{l}\text { Content } \\
(\%)\end{array}$ & $\begin{array}{l}\text { Recovery } \\
(\%)\end{array}$ \\
\hline FROJ & 600.00 & 0.83 & \\
Crude extract & 268.80 & 1.83 & 98.52 \\
TSS-enrichment fraction & 29.27 & 13.86 & 82.68
\end{tabular}




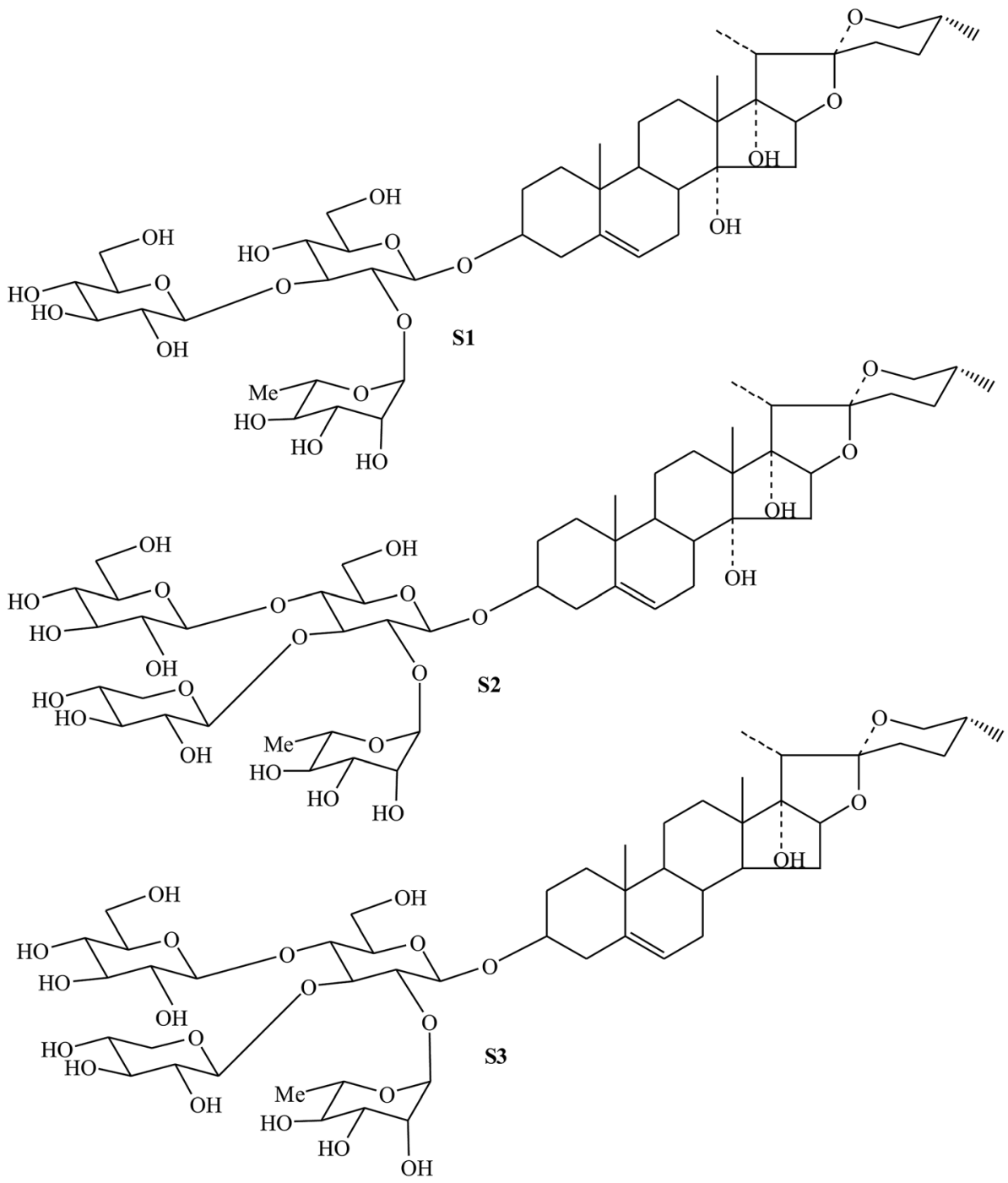

Fig. 6 Chemical structures of steroidal saponins (S1, S2 and S3) from resin-enrichment fraction in FROJ.

concentration increased to the maximum at the second $\mathrm{BV}$, and decreased to a low concentration at the sixth BV. Hence, $6 \mathrm{BV}$ of desorption solution was applied in the further scale-up test.

\subsection{Lab scale-up separation and identification of three steroidal saponins}

The scale-up dynamic enrichment was carried out according to the optimal parameters in dynamic adsorption and desorption tests. As listed in Table 5, the TSS content increased from 1.83\% $(\mathrm{w} / \mathrm{w})$ to $13.86 \%$ with a recovery yield of $82.68 \%$ after the resin enrichment. After further separation and purification, three steroidal saponins (S1-3) were isolated from the XAD-7HP resinenrichment fraction (Fig. S1†).

S1 was isolated as an amorphous solid and gave a positive Liebermann-Burchard reaction. Its molecular formula was assigned to be $\mathrm{C}_{45} \mathrm{H}_{72} \mathrm{O}_{19}$ by the HRESI-QTOF-MS quasimolecular ion peak at $\mathrm{m} / z$ 961.4681 [M $+\mathrm{COOH}]^{-}$(Fig. S2 $\dagger$ ). The ${ }^{1} \mathrm{H}$-NMR spectrum of $\mathrm{S} 1$ shows four methyl groups of $\delta 0.68$ $(3 \mathrm{H}, \mathrm{d}, J=5.5 \mathrm{~Hz}), 1.28(3 \mathrm{H}, \mathrm{d}, J=7.2 \mathrm{~Hz}), 1.11(3 \mathrm{H}, \mathrm{s})$ and 1.15 $(3 \mathrm{H}, \mathrm{s})$ and one olefinic proton of $5.43(1 \mathrm{H}, \mathrm{br} . \mathrm{s})$, indicating the sapogenin skeleton character of $\mathrm{S} 1$. The ${ }^{13} \mathrm{C}-\mathrm{NMR}$ spectrum displayed 45 carbon signals, including 27 carbons of steroidal skeleton and the other 18 carbons due to three monosaccharide moieties (Table S1 $\dagger$ ). According to the above MS and NMR data analysis and comparison of the NMR data with a previous report, ${ }^{34} \mathrm{~S} 1$ was identified as cixi-ophiopogon $\mathrm{C}$.

Similarly, by comparing with the published data of MS, ${ }^{1} \mathrm{H}$ NMR and ${ }^{13} \mathrm{C}$ NMR in previous literatures, ${ }^{4,35}$ their structures were identified as cixi-ophiopogon B (S2), and pennogenin-3-O$\alpha$-L-rhamnopyranosyl-( $1 \rightarrow 2)$-[ $[\beta$-D-xylopyranosyl-( $1 \rightarrow 3)]$-[ $\beta$-Dglucopyranosyl-(1 $\rightarrow$ 4)]- $\beta$-D-glucopyranoside (S3) (Fig. 6), respectively. These characteristic steroidal saponins were previously isolated only from Ophiopogon japonicus cultivated in Zhejiang province, China. ${ }^{4,35}$

\subsection{The inhibition of three steroidal saponins on ox-LDL- induced HUVECs injury}

Research in recent years suggests that atherosclerosis begins with endothelial cell injury, and ox-LDL, as the markers and detectors of atherosclerosis, participated in the occurrence and 

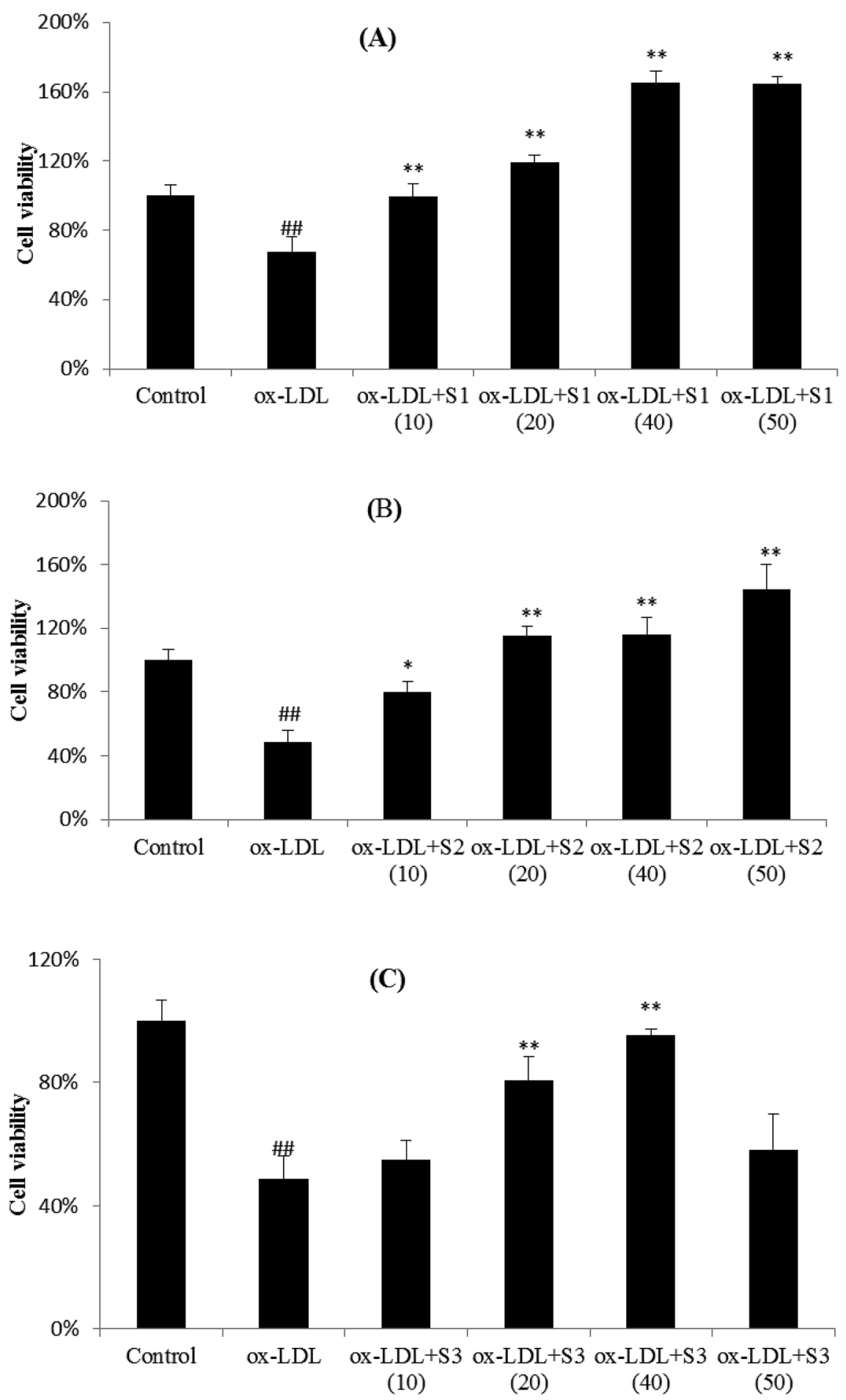

Fig. 7 Cell viability of HUVECs assayed by CCK-8 $(n=5$; the control group was prepared by using the same volume of DMSO and the ox-LDL group was prepared by mixing the same volume of DMSO and ox-LDL). (A) S1 group; (B) S2 group; (C) S3 group; *p< 0.05 vs. Ox-LDL group, **p< 0.01 vs. ox-LDL group, \#\#p < 0.01 vs. control group.

development of the atherosclerosis. Ox-LDL can induce vascular endothelial cells (EC) and mononuclear macrophages to express adhesion molecules, chemotactic cytokines, proinflammatory factor and other mediators of inflammatory responses. Therefore, ox-LDL is the potential inducers of inflammatory process and a strong inducer of endothelial cell adhesion. In vitro experiments showed that ox-LDL could directly damage the surface layer of EC and induce the expression of ICAM-1, VCAM1, and E-selectin in blood vessels, which promotes the infiltration of immune cells, monocyte and lymphocyte adhesion to endothelial, and then migrated into the subcutaneous. Monocytes differentiate into macrophages, which expresses and 
recognizes the scavenger receptor of ox-LDL, cholesterol deposition, foam cells formation and then atherosclerosis occurs. ${ }^{36-38}$ Therefore, the injury model of cardiovascular endothelial cells caused by ox-LDL is often used to study the mechanism of cardiovascular diseases, so as to find potential compound for the treatment of cardiovascular diseases.

As shown in Fig. 7, ox-LDL was able to cause the significant decrease in cell viability as compared with unstimulated cells, and pretreatment of cells with three steroidal saponins markedly attenuated the ox-LDL effects on cell injury in a dosedependent manner. It can be seen that the cell viability of HUVECs slightly increased after treatment with $10 \mu \mathrm{mol} \mathrm{L}^{-1}$ of three compounds, and gradually grew up from 20 to $40 \mu \mathrm{mol}$ $\mathrm{L}^{-1}$, then reached a fairly peak value (except for a decrease of S3 at $50 \mu \mathrm{mol} \mathrm{L}{ }^{-1}$ ). The relatively lower inhibition of S3 also indicated that $\mathrm{C} 14-\mathrm{OH}$ in sapogenin skeleton probably play an important role in cell viability. As another steroidal glycoside and an active component extracted from O. japonicus, Ophiopogonin D (OP-D) has previously been proved to be capable of protecting endothelial cells from $\mathrm{H}_{2} \mathrm{O}_{2}$-induced oxidative stress, which directly inhibits mitochondrial ROS generation stimulated by $\mathrm{H}_{2} \mathrm{O}_{2}$ and also inhibits $\mathrm{H}_{2} \mathrm{O}_{2}$-induced inflammatory responses and redox-sensitive signal transduction. ${ }^{39}$ In our experimental results, it also suggested that three steroidal saponins can effectively protected HUVEC cells from ox-LDLinduced cell death, and may be pharmacodynamics substances for cardiovascular protection in Zhejiang $O$. japonicus.

\section{Conclusions}

In summary, XAD-7HP resin was chosen as the optimal macroporous resin for TSS enrichment from the FROJ. The static and dynamic adsorption characteristics of systematically investigated. With the optimal conditions in lab scale-up separation, the contents of TSS in the resin-enrichment fraction increased 7.59 -folds and the recovery was $82.68 \%$. Three characteristic steroidal saponins were obtained from the resin -enrichment fraction, and showed protective effects against oxLDL-induced endothelium injury. Therefore, XAD-7HP adsorption resin is an effective strategy for enrichment of TSS from FROJ, and FROJ has the potential for functional food and pharmaceutical application.

\section{Conflicts of interest}

We declare that we have no conflict of interest.

\section{Acknowledgements}

This research was supported by Zhejiang Provincial Natural Science Foundation of China (No. LY16C020002), Zhejiang Science and Technology Project (No. 2018C02054) and National Key Research and Development Program of China (2017YFF0207804, 2016YFF0201904).

\section{Notes and references}

1 Y. F. Zhou, J. Qi, D. N. Zhu and B. Y. Yu, Chin. J. Nat. Med., 2008, 6(3), 201-204.

2 Y. Liu, L. Z. Meng, S. X. Xie, T. H. Xu, L. K. Sun, T. H. Liu, Y. J. Xu and D. M. Xu, J. Asian Nat. Prod. Res., 2014, 16(10), 982-990.

3 L. Wang, X. L. Jiang, W. M. Zhang, F. Li, A. A. Khan, X. Liu, K. Yu and M. H. Wang, Phytochemistry, 2017, 136, 125-132.

4 Y. Wu, S. X. Bi, Z. Huang, J. Qi and B. Y. Yu, RSC Adv., 2018, 8, 2498-2505.

5 M. H. Chen, X. J. Chen, M. Wang, L. G. Lin and Y. T. Wang, J. Ethnopharmacol., 2016, 181, 193-213.

6 B. Y. Yu, Chin. J. Nat. Med., 2007, 5(1), 10-14.

7 Y. F. Zhou, J. Qi, D. N. Zhu and B. Y. Yu, Chin. Chem. Lett., 2008, 19(9), 1086-1088.

8 C. L. Duan, X. F. Ma, Y. Jiang, J. X. Liu and P. F. Tu, J. Asian Nat. Prod. Res., 2010, 12(9), 745-751.

9 C. L. Duan, Y. J. Li, P. Li, Y. Jiang, J. X. Liu and P. F. Tu, Helv. Chim. Acta, 2010, 93, 227-232.

10 C. L. Duan, Y. Wang, X. F. Ma, Y. Jiang, J. X. Liu and P. F. Tu, Chem. Nat. Compd., 2012, 48(4), 613-615.

11 S. Lan, F. Yi, L. Shuang, C. J. Wang and X. W. Zheng, Fitoterapia, 2013, 85, 57-63.

12 Z. Y. Kang, M. J. Zhang, J. X. Wang, J. X. Liu, C. L. Duan and D. Q. Yu, J. Asian Nat. Prod. Res., 2013, 15(12), 1230-1236.

13 T. Feng, S. Lan, C. J. Wang, F. Yi and X. W. Zheng, Chem. Nat. Compd., 2014, 50(4), 732-734.

14 J. Qi, Z. F. Hu, Y. F. Zhou, Y. J. Hu and B. Y. Yu, Chem. Pharm. Bull., 2015, 63(3), 187-194.

15 Y. Dong, M. Zhao, D. X. Sun-Waterhouse, M. Z. Zhuang, H. P. Chen, M. Y. Feng and L. Z. Lin, Food Chem., 2015, 168, 538-545.

16 P. Huang, Q. Zhang, H. Y. Pan, L. J. Luan, X. S. Liu and Y. J. Wu, Sep. Purif. Technol., 2017, 175, 203-212.

17 Q. J. Cao, L. S. Wang, H. U. Rashid, H. M. Liang, X. Liu and P. Xie, Sep. Sci. Technol., 2018, 53(5), 745.

18 Y. Kong, M. M. Yan, W. Liu, C. Y. Chen, B. S. Zhao, Y. G. Zu, Y. J. Fu, M. Luo and M. Wink, J. Sep. Sci., 2010, 33, 22782286.

19 L. Xi, T. H. Mu and H. N. Sun, Food Chem., 2015, 172, 166174.

20 J. Kim, M. Yoon, H. Yang, J. Jo, D. Han, Y. J. Jeon and S. Cho, Food Chem., 2014, 162, 135-142.

21 P. C. Sun, Y. Liu, Y. T. Yi, H. J. Li, P. Fan and C. H. Xia, Food Chem., 2015, 168, 55-62.

22 M. Yang, F. Zou, Q. X. Shi, S. M. Ji, X. Y. Wang, X. L. Xiang, W. Li, S. H. Jin, R. Z. Huang and C. W. Song, J. Liq. Chromatogr. Relat. Technol., 2018, 41(4), 188-195.

23 Y. Q. Xu, F. Cai, Z. Y. Yu, L. Zhang, X. G. Li, Y. Yang and G. J. Liu, Food Chem., 2016, 194, 650-658.

24 Y. Y. Shi, T. T. Liu, Y. Han, X. F. Zhu, X. J. Zhao, X. J. Ma, D. Y. Jiang and Q. H. Zhang, Food Chem., 2017, 217, 461-468. 25 Chinese Pharmacopoeia Commission, Pharmacopoeia P. R. China, China Medical Science and Technology Press, vol. I, 2015, pp. 155-156. 
26 Y. F. Wu, L. Zhang, J. W. Mao, S. H. Liu, J. Huang, Y. R. You and L. H. Mei, J. Chromatogr. B: Anal. Technol. Biomed. Life Sci., 2016, 1028, 231-236.

27 Y. L. Zhang, X. Q. Cao, W. W. Zhu, Z. H. Liu, H. H. Liu, Y. D. Zhou, Y. J. Cao, C. F. Liu and Y. Xie, Oxid. Med. Cell. Longevity, 2016, 2016, 1-13.

28 J. L. Pan, Y. Yang, R. Zhang, H. W. Yao, K. K. Ge, M. Y. Zhang and L. Ma, J. Chromatogr. B: Anal. Technol. Biomed. Life Sci., 2017, 1070, 7-14.

29 Y. Chen, W. J. Zhang, T. Zhao, F. Li, M. Zhang, J. Li, Y. Zou, W. Wang, S. J. Cobbina, X. Y. Wu and L. Q. Yang, Food Chem., 2016, 194, 712-722.

30 K. K. Li, X. L. Zhou, C. L. Liu, X. R. Yang, X. Q. Han, X. G. Shi, X. H. Song, C. X. Ye and C. H. Ko, J. Chromatogr. B: Anal. Technol. Biomed. Life Sci., 2016, 1011, 6-13.

31 L. Y. Yao, Y. X. Zhu, C. Q. Liu, R. H. Jiao, Y. H. Lu and R. X. Tan, J. Chromatogr. B: Anal. Technol. Biomed. Life Sci., 2015, 989, 122-128.
32 X. Jin, M. Y. Liu, Z. X. Chen, R. K. Mao, Q. H. Xiao, H. Gao and M. J. Wei, J. Chromatogr. B: Anal. Technol. Biomed. Life Sci., 2015, 1002, 113-122.

33 C. Jampani, A. Naik and K. Raghavarao, Sep. Purif. Technol., 2014, 125, 170-178.

34 Y. Y. Wang, J. Z. Xu, L. Zhang and H. B. Qu, Nat. Prod. Res., 2011, 25(1), 31-35.

35 J. J. Chen, Z. L. Zhu and S. D. Luo, Acta Bot. Yunnanica, 2000, 22(1), 97-102.

36 E. O. Apostolov, S. V. Shah, E. Ok and A. G. Basnakian, Arterioscler., Thromb., Vasc. Biol., 2007, 27(4), 826-832.

37 S. J. Lin, S. K. Shyue, P. L. Liu, Y. H. Chen, H. H. Ku, J. W. Chen, K. B. Tam and Y. L. Chen, J. Mol. Cell. Cardiol., 2004, 36(1), 129-139.

38 H. C. Ou, F. P. Chou, W. H. Sheu, S. L. Hsu and W. J. Lee, Arch. Toxicol., 2007, 81(6), 421-432.

39 J. Qian, F. Jiang, B. Wang, Y. Yu, X. Zhang, Z. Yin and C. Liu, J. Ethnopharmacol., 2010, 128, 438-445. 